\title{
Eve Adamson
}

\section{Frankenstein's Monster in the Arctic Circle}

I shall seek the most northern extremity of the globe . . collect

my funeral pile and consume to ashes this miserable frame, that its remains may afford no light. . . .

The sun set in the sea; the same odd sun rose from the sea,

and there was one of it and one of me.

An alpine glacier carves the streambed,

With its rock-encrusted, dirty snout,

Into a generous $\mathrm{U}$. The snowfield

Glitters beneath the indigo sky

For no one but the ptarmigans

And the infrequent traveler.

The stunted sedges, rushes, heather,

Stand upright. Why shouldn't I?

I sleep beneath a queerly perched

Erratic of basalt. It juts out

Like the spout of a primordial teakettle

Gleaming with glacial polish.

My lemmings (I have a fatherly affection)

Gallop in mad, dwarfish herds

Across the tundra, play, breed, die.

They are sagacious company.

My carnivorous, platonic mate,

The polar bear, grates out groans

Too obscene to imitate,

But leaves me tokens of blue fish 
Scooped from the milky meltwater.

I can depend on him. I dream

Of Milton as I lie in the dark:

"Seest thou yon dreary plain,

Forlorn and wild, the seat of desolation, Void of -" what? Memory fails. What, Beneath the heavy crust of snow?

Geography? I may never know.

Just at the moment when an arctic fox

Or a snowy owl snatches a lemming away,

"Too well I see and rue the dire

Event." Too well I feel it.

To the south, a patch of fuchsia buds

Blows open. How can color explode

Out of such a white place?

The lemming population's blossoming-

They'll be running off the cliffs

Come March. I've learned not to move.

I stand in the shadow of a sacerdotal horn.

Its sharp arretes cast the surface

In high relief. I've named it Mount Paradise, Gained or Lost, depending

On the season, the hour, The temperature of wind. 